\title{
Improving Operations Strategy: Application Of TOC Principles In A Small Business
}

Amarpeet S. Kohli, University of Southern Maine, USA

Mahesh Gupta, University of Louisville, USA

\begin{abstract}
This paper demonstrates how small business managers can create and sustain competitive advantage by applying basic principles of Theory of Constraints (TOC) using a case study on a small family-owned pizza restaurant. TOC five focusing steps were used to reveal the business constraints and practical recommendations were provided that significantly improved throughput, resource utilization, and customer satisfaction without incurring any significant expenses. TOC performance measures encourage small business managers to find innovative ways of increasing throughput instead of simply cutting costs. Positive outcomes in this study demonstrate how small businesses effectively manage their operations and realize benefits using TOC principles.
\end{abstract}

Keywords: Theory of Constraints, Small Business Application, Operations Strategy

\subsection{INTRODUCTION}

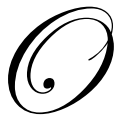

perating effectiveness, when based on capabilities embedded in company's people and operating processes, can provide the basis for a sustainable competitive advantage. It is imperative for small businesses to configure and manage their operations to support business strategies and establish themselves as aggressive competitors (Hayes \& Upton, 1998). Small businesses that neglect operations functions risk the danger of not staying ahead of the competition. Companies that adopt operations management philosophies such as total quality management (TQM), just-in-time (JIT), and theory of constraints (TOC) are ahead in the game and are reaping benefits. These concepts advocate for a change in the operations management paradigm through continuous improvement and if used effectively help managers identify their organizational goals and constraints. That in turn leads to better performance and improved solutions (Motwani et al., 1996). The overall objectives of these philosophies are similar i.e., improving profitability of the business and satisfying customer needs. However, their focuses differ tremendously: TQM emphasizes doing the right things the first time, IT stresses lean manufacturing, and TOC concentrates on the constraints - the weakest link in the chain.

The purpose of this paper is to demonstrate how operations assist small business managers in creating and sustaining a competitive advantage by applying the basic concepts and principles of TOC using a case study. We analyze operations of a small family owned pizza restaurant (we will call it 'The DT Pizza Company' in order to respect the confidentiality of the real business) and apply TOC-based management philosophy to increase operations effectiveness and efficiency, directly resulting in improved financial successes. The remainder of the paper is organized as follows. Section 2 presents a brief review of the literature on TOC. Section 3 expands on application of TOC in relation to the DT Pizza Company by discussing the organizational mindset as well as the performance measures beings employed there. Section 4 reports analysis and application of the five focusing steps of TOC employed in this study. Section 5 provides the details of the implementation of recommended solutions at the DT Pizza Company, and finally Section 6 concludes with recommendations for further research and application in business world.

\subsection{LITERATURE REVIEW}

Theory of Constraints (TOC), an emerging philosophy, was originally developed by Goldratt (1994) to demonstrate how to effectively manage organizations and is based on two assumptions: (1) systems thinking, and (2) 
constraint management (Breen, Burton-Houle, \& Aron, 2002). The primary focus is on continuous improvement which in turn results in enhanced organizational performance. A number of studies have been conducted in the past on application, limitations, and beneficial uses of TOC. Lockamy and Cox (1994) discussed the possibility of using basic concepts of TOC as an aid in successful JIT implementation. Atwater and Chakravorty (1995) demonstrated the value of using TOC to implement TQM based quality improvement projects in a manufacturing company. Dettmer (1997) attempted to explain why TQM efforts fail by using the thinking processes of TOC and provided insights on the effective implementation of TQM programs. Mabin and Balderstone (2000), in their review of over 100 TOC applications, reported that on average, inventories were reduced by $49 \%$, production times measured in terms of lead-times, cycle times or due date performance improved by over $60 \%$, and financial performance also improved by over $60 \%$.

Consequently, a growing number of companies in the U.S. and abroad have begun implementing TOC based operations management philosophy. Both books and academic journals have reported cases in which companies have achieved operational excellence by means of focused process improvement and effective management and scheduling of constraint resources (Cox \& Spencer, 1998; Spencer, 2000; Kendall, 1997; Noreen et al., 1996; Womack \& Flowers, 1999). Recent research on applications of TOC also indicates similar benefits (Boyd \& Gupta, 2004; Mabin \& Balderstone, 2003; Pegels \& Watrous, 2005; Simatupang et al., 2004; Steele et al., 2005; Umble et al., 2006).

However, applications of TOC in the service sector are comparatively restricted. Only few authors have investigated and provided evidence of improved performance using TOC. Motwani et al. (1996) illustrated how TOC can not only be applied in service organizations like Health Care Clinics but also in case of not-for-profit i.e. Red Cross. The study also revealed that TOC measures (throughput, operating expense, and inventory) can be identified and measured to achieve global organization's goal. Siha (1999) asserted that the recognition of organization constraints play an important role in achieving continuous improvement in service organizations. Techniques like drum-buffer-rope which are predominantly common in manufacturing arena can very well be applied in service sector to exploit system constraints and then subordinate resources to it. Breen et al. (2002) described how TOC provided a logical method of improving performance of health care enterprise. Similarly, Polito et al. (2006) used TOC to improve competitiveness in an airline industry. A study conducted by Gupta and Kline (2008) proposed a framework to improve clinician efficiency and reduce waiting times in case of mental health care agency. Similarly, a recent study by Reid (2008) provided a detailed description on how five focusing steps of TOC can be used to improve the performance of a banking system by drawing the management's attention to system's/subsystem's control point. Even though the above literature clearly shows successful examples of how TOC philosophy can be applied in service sector, its application and beneficial use in small businesses is not well documented and needs to be investigated.

\subsection{TOC: A SMALL BUSINESS APPLICATION}

TOC seeks to help business owners maintain a proper focus on system constraints. It recognizes that system constraints limit the performance of a system and, thus, suggests a unique approach to manage these constraints. TOC-based management philosophy focuses on change at three levels (the 3Ms): mindset of the organization, measures that drive the organization, and methods employed within the organization (Srikanth \& Robertson, 1999; Boyd and Gupta, 2003; Gupta and Boyd, 2008).

\subsection{Organizational Mindset in the DT Pizza Company}

TOC concept of throughput-world thinking (TWT) implies that the goal of a company is to make more money (not to save money or reduce costs). Such an organizational mindset further stipulates that certain necessary conditions should never be violated when making decisions in a company in order to achieve the profit goal. Two such important conditions generally discussed in TOC literature are: (a) provide a satisfying work environment to employees, and (b) provide satisfaction to the market (Dettmer, 1998; Goldratt, 1992). Thus, TOC management philosophy argues that a small business should not let the quality of the product (i.e., customer satisfaction) and working environment (i.e., employees' security) become a constraint towards making more money. 
The DT Pizza Company focuses on providing high value to the customers rather than reducing costs. In other words, the prevailing organizational mindset is consistent with TWT. Since 1978, the company has aimed to differentiate itself in the food services industry. Consistent with the overall differentiation strategy, the DT Pizza Company's operational mission is to "serve the best tasting pizza in town---anyway you want it". An interesting aspect of their operations strategy is that the customers can bring their own toppings to create a truly customized pizza and thus, get directly involved with the process. The operational objectives are prioritized to accentuate that operational mission. The operational goals are organized as follows (in order of decreasing priority): 1) quality, 2) flexibility, 3) dependability, and 4) efficiency. The DT Pizza Company achieves quality by integrating informal quality control practices and making each pizza from scratch. Without belaboring the minute details, the owner expects pizzas that are evenly topped, baked without bubbles, and aesthetically pleasing to the eye. To ensure flexibility, they forego sales to provide a stellar product (actually a variety of products including various types of sandwiches, salads, soft drinks, and beer, in addition to their main product, a variety of pizzas) to their existing customer base.

\subsection{Performance Measures in the DT Pizza Company}

Assuming that a firm's goal is to make more money, TOC proposes a performance measurement system consisting of three simple measures: Throughput, Inventory and Operating Expenses. Throughput $(\mathrm{T})$ is "the rate at which the system generates money through sales". It refers to money coming into the business through what is actually sold (i.e., Sales Revenues - Truly Variable Costs e.g., direct materials). If the system produces a product which is not sold, it is not considered throughput. In the DT Pizza Company the main source of generating Throughput is from the sale of 20 different types and 4 different sizes of pizzas (the company also sells sandwiches, salads, soft drinks and beer). More specifically, the throughput per unit of specific pizza is determined by selling price minus truly variable costs (i.e. cheese, flour, yeast, lard, vegetables, and meat). The management stated that $40 \%$ of the sales revenue is direct material cost; hence the Throughput is $60 \%$ of the sales.

Inventory (I) is "all the money invested in purchasing the things the system intends to sell". It represents the money currently stuck inside the system. It encompasses all assets i.e. properties, furniture, and equipment used in operations in addition to the traditional inventory comprising of raw materials, work-in-process and finished goods. The Inventory at the DT Pizza Company consists of traditional inventories such as daily supply of work in progress and one week's supply of direct materials as well as other equipment and assets such as an industrial mixer, several pans and bins, four ovens, a dough sheeter, restaurant furniture, and fixtures.

Operating Expenses $(\mathrm{OE})$ is "all the money the system spends in turning inventory to throughput". It represents all the money going out of the system which includes selling and administrative expenses, utilities, rent, supplies, salaries and wages, and other over-heads. The operating expenses at the DT Pizza Company consist of salaries and wages, operational overheads (i.e., waste, depreciation, utilities, and maintenance), administrative expenses, license fees, and rent.

These TOC-based performance measures are: (a) financial in nature [they can be translated in financial measures such as Net Profit (i.e., T-OE), Return on Investment (i.e., (T-OE)/I), and Cash Flow (i.e., T-OE $+\Delta \mathrm{I})]$, (b) easy to apply at any level of a company, and (c) global in nature i.e. ensure that local decisions are aligned with the profit goal of the firm (Goldratt, 1990, pp 19-51). Thus, the organizational mindset promotes a managerial decision resulting in a simultaneous increase in throughput, as well as reduction in inventory and operating expenses. Without getting into specific financial information, in the following section, we will show that these TOC based performance measures allow small business managers to analyze various decisions they make on day to day in terms of their impact on $\mathrm{T}$, I, and $\mathrm{OE}$.

\subsection{Five-Focusing Step Methodology for Improving DT Pizza Company Operations}

TOC stresses that every business system has at least one constraint (or few at maximum) defined as anything that limits a system from achieving higher performance versus its goal. A five-focusing step process is proposed (Figure 1) for managing constraints and continuously improving the system. 


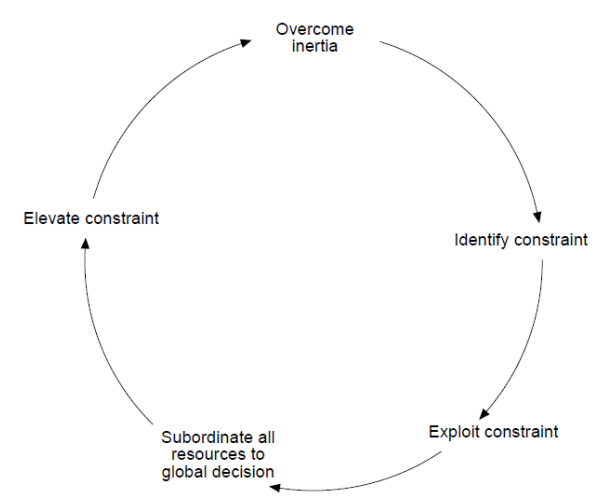

Figure 1: TOC Process of Ongoing Improvement Source: Adapted from Rahman (1998)

First, IDENTIFY the system's constraint(s). Second, decide how to EXPLOIT the system constraint(s) i.e. get the maximum possible within the limit of the current constraints by increasing throughput without incurring any operating expenses or investing more money. Third, SUBORDINATE everything else to the above decision i.e., avoid keeping non-constraint resources busy doing unneeded work. Forth, ELEVATE the system constraint(s) i.e., if actions taken in the previous two steps fail to break the constraint, off-load some demand or purchase additional capacity for the constraint(s). Finally, if in the previous steps a constraint has been broken, go back to step 1 but DO NOT allow INERTIA to cause a system constraint i.e., revisit all the decision taken in the previous steps and continue the improvement process. In the DT Pizza Company we analyzed the operations and applied five-focusing steps to manage the system constraint(s) and generate a set of practical common sense recommendations which are discussed in the following sections.

\subsection{ANALYSES AND APPLICATION OF FIVE-FOCUSING STEPS OF TOC}

The major challenge for the operations manager/owner at the DT Pizza Company was to create sufficient capacity to "keep up with demand". While the company is generally successful in this regard, peak periods have continually experienced a capacity shortage, which has resulted in unmet demand during this time period. From Sunday through Thursday, demand equates to approximately 60 pizzas daily with capacity ranging anywhere between 24-48 pizzas per hour depending on the size and number of toppings. During peak periods on Friday, Saturday and Sunday evenings, demand jumps to 200 pizzas. According to the business manager/owner, there simply was not sufficient capacity to meet customers' demand during the peak periods. The owner attributed this to an inoperative oven. Based on the following analysis of the production capacities of various processes, however, we derived an alternative conclusion and suggested a number of practical common sense solutions, which can be (and as of now have been) implemented by the company.

\subsection{Operations Flow Analysis in the DT Pizza Company}

Since the main product and the major source of income for the DT Pizza Company is, as the name suggests, pizza, we selected corresponding product for more thorough analysis. The pizza making procedure consists of three main processes: (i) order taking process, (ii) pizza preparing process, and (iii) pizza baking process (see Figure 2).

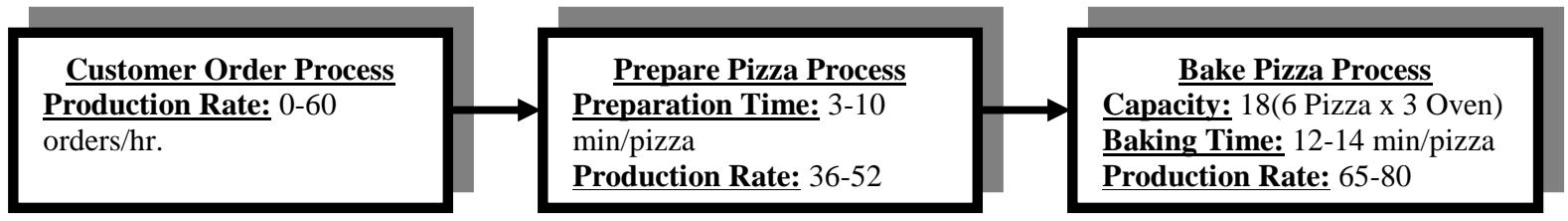

Figure 2: Production Capacity Analysis of the Pizza Making Process 
When customers arrive in the evening, orders are placed with a family employee who "calls out" the order to workers responsible for making the pizza. Customers pay for their food when they place the order. The rate at which customer orders are received can vary significantly within any given hour. During peak times the restaurant can receive more than 60 orders, though that is not always the case. Then, the actual pizza preparing process begins. First, the workers sauce the sheeted pizza dough. The sauced pizza is then moved to the next station, where the pizza is topped with custom ingredients. (Note: The pizza preparing process is setup early in the morning with the preparation of large bins containing the sauce and pizza toppings. These bins are refreshed periodically throughout the day). The time to prepare a pizza depends on the size, the number of toppings and the types of toppings. The timings observed were about 3-4 minutes for a small pizza, 4-6 minutes for a family size pizza and 7-10 minutes for a special large pizza. There are four pizza-making stations, and family pizzas are the most popular pizzas ordered. Based on these facts, the estimated rate for the process is 36-52 Pizza/Hr (4 stations * 60/6.6 Average high time - 4 stations *60/4.6 Average low time).

Next, the pizza is transferred to the oven, where it is monitored regularly during baking until completion. Pizzas are made to order so if there are no orders the oven has idle capacity, and as orders start coming in, the oven starts to get utilized. Unlike the "Prepare Pizza" process the oven used to bake the pizza has a fixed capacity with limited variance, meaning that when there are large numbers of orders, employees are in a hurry to catch up on the orders, but the oven has a finite capacity. There is no way to speed up the baking process, so if the oven is filled to the capacity, there could be times when pizzas are prepared and waiting to go into the oven. There are three ovens with a capacity to place 6 pizzas in each, and the time each pizza is placed in the oven varies between 12-14 minutes. Thus, on average, baking process can produce 65-80 pizzas per hour. Finally, when the pizza is removed from the oven, it is immediately delivered to the customer.

\subsection{Identify the System's Constraint}

In order to identify the constraint, we observed the process at peak time and also interviewed the management. During our preliminary investigation we identified two primary constraints: the pizza making process and the oven. At peak times customer orders were not the constraint, as there were more orders coming in than the system could process, so the market was not a constraint. The management said that they stop accepting telephonic orders after more than 20 orders are pending. On further investigation of the production rates (as discussed in the previous section and illustrated in Figure 1), we conclude that the pizza preparing process is a bottleneck.

\subsection{Decide How to Exploit the System's Constraint(s)}

The next step in the ongoing process of improvement is to decide how to exploit the constraint. The company should take actions that ultimately increase the production capacities of the bottleneck process. Any time wasted on this process represents the lost throughput and therefore, profits for the company. In an effort to offer suggestions to exploit the constraint we studied the constraint i.e., pizza preparing process in more detail.

There are a number of activities involved in the preparing pizza process. When a customer order is received, it is written on an order book at the register that is shared by all four pizza-preparing stations. An employee on one of the four available stations starts to work on the order. The first activity is to get the sheeted pizza dough kept in a bin on the side. Once the pizza dough is fetched, it is placed on a wooden board. One wooden board is used to assemble two pizzas and is shared by two people. Pizza sauce is applied on the dough. The second activity involves weighing the cheese kept in the bin. The third activity is to spread the weighed cheese evenly on the sauced pizza dough. Next, desired toppings are checked from the order book at the register and toppings are put on the pizza one at a time. When both pizzas on the wooden board are ready and quality is checked, the board is moved to the baking station to be baked. We further analyzed the time spent on some of these activities and interviewed the owner in order to find methods to exploit the constraint. Our observations are summarized on Table 1. The last (desired) column of the table shows the times that can be attained with minor process adjustments. Based on these observations we are suggesting the following recommendations to exploit the constraint: 
Table 1: Analysis of the Pizza Preparation Process

\begin{tabular}{lccc}
\hline \multicolumn{1}{c}{ Activity } & Minimum (seconds) & Typical (seconds) & Desired \\
\hline Reading the order & 30 & 30 & 20 \\
Sauce and cheese & 30 & 60 & 5 \\
Topping the pizza & 180 & 270 & 180 \\
Refresh bins & 10 & 15 & 10 \\
Waste** & 10 & 10 & 5 \\
Totals & $4 \mathrm{~min} 20 \mathrm{sec}$ & $6 \mathrm{~min} 25 \mathrm{sec}$ & $3{\mathrm{~min} 35 \mathrm{sec}^{*}}$ \\
\hline
\end{tabular}

*The rate of $3 \mathrm{~min} 35 \mathrm{sec}$ means $67 \mathrm{Pizza} / \mathrm{Hr}$ which is slightly more than lower end of the oven capacity.

** Time to rework pizza (i.e., wrong topping etc.) and other QC problems

The art of topping a pizza improves with experience. While we were observing at the DT Pizza Company, we noticed that the rate and the ease at which the pizza was topped varied from person to person. We also learned that there are several "tricks" that can reduce the time taken to top the pizzas. For example, dipping one's hand in the olive bin prior to adding sausage can significantly reduce the time required for sausage topping. Therefore, we suggest that this knowledge be distributed through some informal training to all employees. We also recommend offering incentives to employees for making good pizzas at the desired rate (i.e., orders are read correctly, and toppings are spread out in a proper sequence evenly and aesthetically without spending extra time).

The processes of recording and reading the order can be improved by making use of order slips with clips, and retaining a carbon copy for records. The clips are used to place the order in front of the worker at the workstation. Hence each pizza station will have its own order in front of it; thus it can save some valuable time in rubber necking and trying to read the order at the register. This will also increase the probability that the orders are prepared correctly and are not misread. This is important, since we learned that it is relatively common for employees to reach for the wrong topping. This mistake is caught only through the management's supervision. In a worse case scenario the mistake is caught only after the wrong topping has been applied to pizza dough. Removing the wrong topping will in that case waste the valuable time of the constraint resource.

The weighing of cheese is an important step as it ensures uniform quality of the pizza. However, it takes valuable time from the constrained resources; hence, other options should be explored. One way to expedite this process is to store the pizza dough with cheese and sauce already applied during the peak time. When the order is received an employee will get this kind of pre-prepared pizza dough from the bin, and since the sauce and cheese is already on it, the employee can start right away to apply toppings. The inventory for this kind of pre-prepared pizza dough could be adjusted to 10 to 15 units based on the experience and wait time. When the inventory drops below that level one employee uses the table where the bin of sheeted pizza dough is stored to prepare more of these preprepared dough sheets (during the peak periods when the constraint is in pizza preparing process).

Another way to exploit this process is to use a scoop with the right volume which can reduce the time to weigh cheese. This will further speed up the pizza preparing process. After these steps are integrated, we expect that the time to make a pizza can be reduced from $6 \mathrm{~min} 25 \mathrm{sec}$ down to $3 \mathrm{~min} 35 \mathrm{sec}$. This translates into an approximate $40 \%$ increase in production: from 48 pizzas/hour to 67 pizzas/hour. Throughput will increase by almost $11.4 \%$ [(60\% of (67-48)]). The net profit will also increase by the same percentage. In addition, implementing these suggestions reduces material as well as time waste, which results in a somewhat smaller inventory. Thus, this set of recommendations will increase throughput and reduce inventory and operating expenses simultaneously.

\subsection{Subordinate Everything Else to the Above Decisions}

After exploiting the constraint, the next step is to subordinate all non-constraint resources to the constraint, which implies that they should be used to enhance the performance of the constraint resource. Based on our observations, we make the following recommendations with respect to off-loading some of the activities of constraint process to non-constraint resources. While observing the pizza making process, we discovered that at times there is a shortage of processed toppings such as chopped onions and other vegetables in the bins. This results into the constraint resource sitting idle while waiting for the bins to be refilled, especially during the peak time, or wasting the valuable time of the constraint resource. It is possible to refresh the bins, and thereby, maintain an 
adequate supply of the processed material, so that the bins are not starved for the material. Management should consider the option of pricing pizzas based on the utilization of constrained resource. Some toppings, for example sausage, are considerably slower to apply on a pizza than other toppings (e.g., chopped onions). Since the best possible time utilization of the constraint is crucial for the whole organization, toppings requiring a long time to apply should be priced higher than those requiring less application time. Management should also consider offering "Happy Hour" during the peak time (evenings) and peak load days (Friday, Saturday, and Sunday), thereby dividing the load of the peak hours for a longer period of time. This would reduce the statistical fluctuations and smooth out the flow through the constrained resource.

\subsection{Elevate the System's Constraint}

Once the steps highlighted in exploitation and subordination have been considered and implemented, the next step is to elevate the constraint of the system, which involves the decision to purchase the constraint resource so that the overall capacity of constraint is elevated to a higher level. Thus, elevation decisions involve some increase in inventory (i.e. investment) and/or operating expenses which is also the main difference between the set of decisions made in step 2 (exploit) and step 4 (elevation). TOC-based management philosophy suggests that management must implement the 2nd and 3rd steps (i.e., exploit and subordinate) so that everyone is aware of the constraint resource, and management has done what it could without incurring any investment and/or operating expenses. Moreover, management should also decide on the strategic location of the constraint. Generally, the constraint should be located on the process, which is the most expensive and may be hard to elevate. For example, in the DT Pizza Company the oven is the most expensive resource and based on our discussions, management wanted to see the constraint moved to the oven. Keeping this in mind, we suggest following three actions to elevate the current constraint:

- $\quad$ Currently in the pizza preparation process, one wooden board is used for two pizzas and in total two wooden boards are being used. Thus, even if one pizza is ready, it has to wait for the other pizza on the board to be ready before it can go into the oven. Based on this observation, we suggested the implementation of separate boards for each pizza to further decrease statistical fluctuations in the process and increase the capacity. This should be a very inexpensive way of increasing throughput.

- $\quad$ Another possibility for elevating the constraint is, for example, the modification of the working stations, so that bigger bins can be used to store the toppings and, thereby reduce the need for frequent refilling.

- The owners should consider adding another bin station to process pizzas. This would involve hiring at least one more employee at the preparing pizza stage, but it would ensure that all the customer orders could be processed during the peak time. Among the three proposed solutions, this is probably the most expensive solution which should be implemented to move the constraint to the next level.

\subsection{Go Back to Step 1 and not Allow Inertia to Cause a System's Constraint}

The first part of this step makes the five-focusing steps of TOC, a continuous process. The second part is a reminder that no policy (or solution) is appropriate (or correct) for all time or in every situation. It is important for business managers to recognize that the previous decisions made have to be refined as the business environment changes. Once the solutions recommended in the preceding steps are implemented, our current constraint (the pizza preparing process) can increase its capacity up to 85 pizzas/hour, which shows that the oven, due to its limited capacity (i.e., 65-80 pizza/hour), will be the constraint. Thus, we need to start our five-focusing steps again and revisit all the decisions we made in the previous round of improvement process.

\subsection{IMPLEMENTATION OF RECOMMENDED SOLUTIONS}

Following completion of TOC-based operations analysis described above, the business owner was briefed on the recommended solutions. His reaction was favorable and many of the recommendations were implemented without any major hurdles as explained below. The DT Pizza Company manager was in agreement that during peak times, the constraint was in the pizza preparing process and it makes sense to focus improvement efforts to this process. The company now pays close attention to this process during the peak periods. Specifically, the company now ensures that (i) trained personnel are assigned to this process so that toppings are spread out in a proper 
sequence evenly and aesthetically without spending extra time, (ii) bins with processed toppings are refreshed immediately, (iii) workers use scoop to pour instead of weighing cheese, and (iv) order slips with clips are used at each work station to avoid errors made in reading the order and applying wrong toppings. These changes were implemented without any reservations and the increase in Throughput (and thereby the profitability) was confirmed.

The DT Pizza Company did not implement the following recommendations: (i) storing the pizza dough with the cheese and sauce already applied on it due to the various sizes of the pizza dough they had to store, and (ii) pricing the pizza based on the time consumed by some of the toppings, primarily due to its perceived impact on the operations strategy of the company. The owner wanted to further look into the below listed recommendations: (i) offering "happy hour" during the peak periods, (ii) using two wooden board instead of one to prepare the pizza, (iii) using bigger bins to store the toppings, and (iv) adding fifth workstation to prepare pizza. In principle, the owner agreed that the strategic location of the constraint should be the process involving the most expensive resource i.e. oven and the latter set of recommendations when implemented will ensure that the constraint is strategically located.

\subsection{CONCLUSION}

One of the main reasons for the failure of small businesses is reported to be poor and inadequate management. This paper demonstrates how the theory of constraints (TOC), an evolving management philosophy, can be used to improve the operations functions, and thereby the financial health of a small family-owned business. Specifically, we reviewed the business and operations strategy of the DT Pizza Company and found that the company had several strengths, including the loyal customer base and concern for the employees' security consistent with the Throughput world thinking mindset. Next, we developed TOC-based performance measures, i.e., throughput, inventory, and operating expenses for the DT Pizza Company to allow the various management decisions to be analyzed in terms of these measures. The major focus of this paper was to analyze the processes to identify the constraint process and explain how five-focusing steps could be applied to generate practical solutions and put the company on a continuous improvement process. Even with our limited exposure to the pizza making process, we were able to zero in onto the problem in no time and provide cost-effective solutions after understanding the processes of the company. It also provided the business under review insight on where to anticipate the next problem and thus continue the ongoing process of improvement.

\section{AUTHOR INFORMATION}

Amarpreet Kohli is an Assistant Professor at School of Business, University of Southern Maine. He received his $\mathrm{Ph} . D$. in Industrial Engineering from University of Louisville, KY. His research interests include supply chain collaboration, lean management, enterprise resource planning and other operation and supply chain management areas using simulation, theory of constraints, and empirical modeling techniques. Dr. Kohli has published in various peer reviewed journals and presented at national \& international conferences. He is a member of DSI, INFORMS, and POMS. He has more than 10 years of experience in sales and distribution, new product development, and quality assurance in various multinational companies.

Mahesh Gupta is a professor in the Department of Management, University of Louisville. He obtained his MCom from the University of Jammu, India, MSc from the University of Manitoba, Canada, and PhD from the University of Louisville, KY. Dr Gupta has published in numerous journals including International Journal of Operations and Production Management, International Journal of Production Research, European Journal of Operational Research, and Production and Inventory Management Journal. He is a member of DSI and POMS.

\section{REFERENCES}

1. Atwater, J. B., \& Chakravorty, S. (1995). Using the Theory of Constraints to guide implementation of quality improvement projects in manufacturing operations. International Journal of Production Research, 33(6), $1761-1784$.

2. $\quad$ Boyd, L., \& Gupta, M. (2004). Constraints management: What is the theory?" International Journal of Operations \& Production Management, 24(4), 350-371. 
3. Breen, A., Burton-Houle, T., \& Aron, C. (2002). Applying the Theory of Constraints in Health Care: Part 1 - The Philosophy, Quality Management in Health Care, 10(3), 40-46.

4. Cox, J. F. \& Spencer, M. S. (1998). The Constraints Management Handbook. St. Lucie Press, Boca Raton, Florida.

5. Dettmer, H. W. (1997). Goldratt's Theory of Constraints: A Systems Approach to Continuous Improvement. ASQC Quality Press, Milwaukee.

6. Dettmer, H. W. (1998). Breaking the constraints to world class performance. ASQ Quality Press.

7. Goldratt, E. M. (1990). The Haystack Syndrome. North River Press, Inc., Croton-on-Hudson, New York.

8. Goldratt, E. M. (1992). The Goal (2nd Revised Edition), North River Press, Inc., Croton-on-Hudson, New York.

9. $\quad$ Goldratt, E. M. (1994). It's Not Luck. North River Press, Inc., Croton-on-Hudson, New York.

10. Gupta, M., \& Kline, J. (2008), Managing a community mental health agency: A theory of constraints based framework, Total Quality Management \& Business Excellence, 19(3), 281-94.

11. Gupta, M. \& Boyd, L. (2008), Theory of Constraints: A Theory in Operations Management, International Journal of Operations and Production Management, 28(10), 991-1012.

12. Hayes, R. H., \& Upton, D. M. (1998). Operations-based strategy. California Management Review, 40(4), 825.

13. Kendall, G. I. (1997). Securing the Future: Strategies for Exponential Growth using the Theory of Constraints, St. Lucie Press, Boca Raton, Florida.

14. Lockamy, A., \& Cox, J.F. (1994), Reengineering Performance Measurement, Irwin Publishing, New York.

15. Mabin, V. J., \& Balderstone, S. J. (2003), The performance of the theory of constraints methodology: Analysis and discussion of successful TOC applications, International Journal of Operations \& Production Management, 23(5/6), 568-595.

16. Mabin, V. J., \& Balderstone S. J. ( 2000). World of the Theory of Constraints: A Review of the International Literature, St. Lucie Press, Boca Raton, Florida.

17. Motwani, J., Klein, D., \& Harowitz, R. (1996). The theory of constraints in services: Part 1 - the basics. Managing Service Quality, 6(1), 53-56.

18. Noreen, E., Smith, D., \& Mackey, J. T. (1996). The Theory of Constraints and Its Implications for management Accounting, North River Press, Inc., Croton-on-Hudson, New York.

19. Pegels, C. C., \& Watrous, C. (2005), Application of the theory of constraints to a bottleneck operation in a manufacturing plant, Journal of Manufacturing Technology Management, 16(3), 302-311.

20. Polito, T., Watson, K., \& Vokurka, R. J. (2006), Using the theory of constraints to improve competitiveness: An airline case study, Competitiveness Review, 16(1), 44-50.

21. Rahman, S. U. (1998), Theory of constraints: a review of the philosophy and its applications, International Journal of Operations \& Production Management, 18(4), 336-355.

22. Reid, R. A. (2008), Applying the TOC five-step focusing process in the service sector: A banking subsystem, Managing Service Quality, 17(2), 209-34.

23. Siha, S. (1999). A classified model for applying the theory of constraints to service organizations, Managing Service Quality, 9(4), 255 - 264

24. Simatupang, T. M., Wright, A. C., \& Sridharan, R. (2004), Applying the theory of constraints to supply chain collaboration, Supply Chain Management, 9(1), 57-70.

25. Spencer, M. S. (2000). Theory of constraints in a service application: The Swine Graphics case, International Journal of Production Research, 38(5), 1101-1108.

26. Steele, D. C., Phillipoom, P. R., Malhotra, M. J., \& Fry, T. D. (2005), Comparisons between drum-bufferrope and material requirements planning: A case study", International Journal of Production Research, 43(15), 3181-3208.

27. Srikanth, M. L., \& Robertson, S. A. (1999). Measurements for Effective Decision-Making, The Spectrum Publishing Company, Guilford, CT.

28. Umble, M., Umble, E., Murakami, S. (2006). Implementing theory of constraints in a traditional Japanese manufacturing environment: The case of Hitachi tool engineering, International Journal of Production Research, 44(10), 1863-1880.

29. Womack, D. E., \& Flowers, S. (1999). Improving system performance: A case study in the application of the theory of constraints. Journal of Healthcare Management, 44(5), 397-405. 


\section{NOTES}

